\title{
A Study on the Mode of Peer Revision in English Writing Based on WeChat Platform
}

\author{
Rongqin Ma \\ International Education College, Xi’an Peihua University; Xi'an, China
}

Keywords: WeChat platform, English writing, peer revision

\begin{abstract}
Peer revision plays an important role in College English writing teaching. It is the combination of educational function of WeChat platform and the peer revision mode in English writing that forms a new teaching mode in college English writing teaching, to some extent, improve the students' English writing ability.
\end{abstract}

\section{What is the mode of peer revision in English writing?}

English writing is a very important part of English teaching, which has been the consensus of language experts and scholars. English writing is not only an important means of language communication, but also an important indicator of English comprehensive ability. For a long time, English writing has always been the bottleneck of restricting at various levels and English teaching effect, how to build effective and scientific method in English writing, is also the topic which needs the majority of English teachers and researchers to explore. Since the 1970s, education experts have shifted the focus of English writing teaching from traditional "productive writing" to "process writing". The former is that teachers give students directions and students respond to, but this writing mode failed to fully embody the leading position of students learning. Some students complete the writing passively and even ignore the teacher's comments. However, the latter emphasizes that writing is a series of cognitive activities and interactive activities and also the ultimate manifestation of the ability to interact and write. Students' subjectivity has been fully developed in this way of writing, which has stimulated the students' independent thinking ability. The advantages of peer evaluation in writing teaching are constantly improved and amended, which is increasingly prominent in various teaching methods, and is actively explored by education experts at home and abroad. Peer revision, also known as peer feedback, peer review, and peer assessment, etc., refers to an activity of writing teaching in which peers read each other's writing, point out shortcomings and grammatical wrong and modify them. During the process of peers' correction, they provide feedback and suggestion to improve their writing level and achieve progress together. Gauk's studies have shown that peers correction can help improve students' writing as teachers do. Richards believes that students' critical reading ability and analytical ability can be improved with feedback from others and reflect on their own writing during the process of feedback. Peer feedback can not only improve the writer's writing ability but also improve the reader's understanding ability. The views of teaching and learning under the theory of constructivism show that both teaching and cooperation should be centered on students, and the mode of student mutual evaluation matches the theory. When the students finish the first draft, peers give feedback in time, which plays a decisive role in the whole writing process. First, it can arouse the author's reader consciousness, and it is easy for writer to understand readers and their expectations and attitude to the article, which make writer clarify his real aim of communication, and enhance their writing motivation and interest in the following practice; Second, peer revision whose main form is the mutual interaction and negotiation not only can enrich the author's cognitive schema, to enhance its capability of error correction, to improve the depth of information processing, but also can promote the students' ability of social cognition, social interaction and construction of text.

At present "teacher evaluation" is a major teaching mode of in the second language writing teaching. Because students are lack of necessary activities of a collective writing input, reader 
consciousness, writing interest and motivation in the process of writing, the quality of writing cannot be assured. Peer revision and feedback mechanism is the interaction of information and consultation in the process of writing, and also is the core of the writing process, whose purpose is to help students to enhance the reader consciousness, reduce the writing anxiety, make up for their deficiencies and promote the quality of the text output in composition.

In the English writing class in China, the teacher provides a model essay, carries on the analysis explanation, gives the stimulation, and the students imitate the model essay to practice to strengthen what they learned from teachers, and finally the teacher carries on the correction. This kind of teaching mode occupies an important position in college English writing teaching in our country, but it neglects the dominant position of students during learning to a great extent, which is not conducive to the students' enthusiasm to English writing. A positive and effective way of English writing teaching should be explored.

Nowadays college English teaching is still dominated by teacher-centered teaching mode, which is not satisfied with the needs of students and social development. To change this situation, it is necessary to advocate the student-centered teaching method, changing the focus from teaching to learning, and to re-establish the relationship between teaching and learning, namely, the teacher is the leader of teaching activities in class, and the students are the subjects. The teaching model of peer review in English writing based on WeChat platform is the teaching mode which embodies the concept of student-centered teaching method.

\section{The role of WeChat in English teaching.}

College English Teaching Guide clearly points out that college English teaching should fully use Media network and other advanced educational technology, and carry out multimedia teaching and establish network learning platform and adopt the all-around, three-dimensional and network teaching means, so that the consciousness of independent study is fostered, and teaching efficiency and teaching quality is improved. With the development of network and information technology, a sea of target language material such as listening, speaking, reading, writing and so on can be obtained by teachers and students.

WeChat, launched in May 2011 by Tencent Company, is a free application which offers instant messaging service for the intelligent terminal. WeChat possesses many functions, such as supporting across different communication operators and operating systems through nets to fast send free voice messages, video, images and text, etc. By 2017, WeChat had covered more than 95 percent of China's smartphones, with more than 7 billion daily active users. Due to zero restriction of time and space, WeChat has become the first choice of instant communication for modern college students. English educators are also actively exploring effective teaching mode which can combine the communication platforms that many college students prefer to and English teaching. Facts proved that WeChat function "moment" breaks through the limits of time and space of traditional college English teaching, which can act as "bridge" between teachers and students, among classmates and WeChat friends after class. To exchange different opinions and share their own learning achievements is also a beneficial extension of in-class teaching. Any class can use this function to establish the learning platform which fits major-related courses for real-time communication and sharing in this class. The information sent by teachers can achieve quick sharing of learning content and detection of learning tasks on time. The diversified learning environment has expanded the participation of students and also aroused their enthusiasm and initiative.

\section{Specific procedures of the mode of peer revision mode in English writing based on WeChat Platform are as follows:}

Introduce students how to use WeChat platform text, picture, voice, video and other functions related to language learning, and then introduce the main purpose of the peer review mode of English writing and the training exercises for evaluating and modifying methods. (Evaluation and 
modification methods can be based on the written expression ability level of non-English major undergraduates in English teaching objectives.)

Pre-test for students who use "the mode of peer revision mode in English writing based on WeChat Platform", then the average score of the class obtained. (Pre-test content: any topic related to CET-4 composition, within 30 minutes, no less than 120 words, a full score of 15, teachers graded according to CET-4 writing scoring criteria)

Because there exists different English learning ability between the two sides in peer revision group, it could lead to the effect of mutual revision is poor. According to three levels of their English scores (excellent, medium and poor), the class is divided into three study groups in the way of free combination. Set a writing task for a week with writing requirements and methods, teachers can offer some basic information, such as key words, set patterns, and links related to topics in groups which have a rather poor English performance. Students will upload their writing exercises in their WeChat moment or WeChat study groups to review and modify within the given time. Students' uploaded writing were checked selectively by teachers in a way of batch samples and groups and were summarized the results of check through the way of text, voice or video. Students correct their writing according to partners and teacher's evaluation and then upload to group again after making modifications. At the same time students can post corrected writing to WeChat moment and invite friends to evaluate their writing. Teachers can also release students' writing to the other two groups.

Retest after a semester of training and then obtain the average score of the class. (Retest content: any topic related to CET-4 composition, within 30 minutes, no less than 120 words, a full score of 15 , teachers graded according to CET-4 writing scoring criteria).Make a comparison and analysis based on score results of pretest and retest in accordance with individuals, mutual groups and a class, then verify whether the mode of peer revision in WeChat platform does improve the students' English writing and play a promoting role.

After analyzing and comparing the results of pretest and retest, the author summarizes the experience and come up with further improvement methods.

\section{Application effect of the mode of peer revision in English writing based on WeChat Platform}

\subsection{Comparison of two questionnaires.}

Before the experiment, the students' English learning attitude and network awareness were investigated. All students think that writing plays a very important role in English study. Only 5 percent of the students surveyed had used WeChat to study English out of the classroom. At the end of the experiment, a poll was conducted on the learning mode of peer revision in English writing based on WeChat platform to further learn more about the students' feelings about WeChat English writing. It turns out that 80 percent of students think that writing ability is improved; 90 percent think peer review training had an obvious effect, and 10 percent say that it has no effect at all.

\subsection{Pre - and post-test contrast.}

Before the experiment, the average score of the class was 7.28 (according to the writing scoring standard of CET-4). After the experiment, the average score of the class was increased by $16 \%$. From the data, it can be seen that the English writing performance of the class has improved significantly in the mode of peer revision in English writing based on WeChat platform.

\section{Advantages and disadvantages of the mode of peer revision of English writing based on WeChat platform.}

The combination of WeChat platform and peer revision of English writing is a new attempt. In the limited time students can really change the passive mode of writing before, which stimulates the enthusiasm of the students' English writing and promotes the consciousness and initiative of the students' writing. Students are not those who read teachers' comments passively, but those who 
modify composition actively. To a certain extent, the English writing level of students has been improved, meanwhile teachers have been liberated from the heavy marking work as well. The disadvantage of this model is that the students with poor performance in the mutual evaluation group cannot implement effective mutual evaluation due to their weak English foundation, which makes the learning effect not obvious. It may be mainly reflected in the limitation of students' experience and ability, focusing only on superficial problems such as grammar and vocabulary, and failing to make an accurate assessment of the in-depth problems. In the long run, acquisition of language knowledge is affected by both parties, which aggravates the frustration of the two sides and then loses interest in English learning. So teachers should pay more attention to problems arisen in the process of students' mutual evaluation, and help them figure out and overcome the difficulties in order to achieve a better teaching effect.

The function of WeChat auxiliary English teaching conforms to the characteristics of English language learning and the needs of the college English writing teaching, has a strong feasibility, and also is a convenient way to improve the present situation of college English writing teaching and other language ability. But WeChat is just as much a tool as any previous technology, and it is not a sufficient condition for college students to improve their English writing ability. The technical platform should be integrated into other English activities. The mode of peer revision of English writing Based on WeChat platform is also the same. Teachers must carry out the teaching based on their professional knowledge, is not a simple use of WeChat tools and platforms to upload audio, video, and then the students watch the English learning of one-way learning process, and should be a teacher, student, WeChat platform interaction teaching process.

Last but not the least, WeChat education platform can not completely replace the traditional classroom teaching, but as an auxiliary means of classroom teaching in the internet age, it must also be based on classroom teaching. At the same time, teachers should supervise and regulate the students' lines in WeChat platform in order to avoid superficial learning or deviation from the main learning purpose.

\section{References}

[1] https://t.qianzhan.com/caijing/detail/170424-8f9569e1.html

[2] Keh,C.L..Feedback in the Writing Process:a model and methods for implementation [J].ELT Journal,1990,44(4).

[3] Cooper,M.\&Holzman,M..Writing as Social Action[M]. Portsmouth, NH:Boynton Cook; Heinemann,1989.

[4] Gaulk,N..Comparing Teacher and Student Responses to Written Work [J].TESOL Quarterly, 1994, 28(1):181 - 188.

[5] Keh,C.L..Feedback in the Writing Process:a model and methods for implementation [J].ELT Journal,1990,44(4).

[6] Richard,J.C..Second Language Writing [M]. Cambridge: Cambridge University Press, 2003.

[7] Xu ying. A Preliminary Study on the Teaching Methods of English Writing for Middle School Students [J]. Journal of Foreign Affairs,2000(4).

[8] Wang Duqin. The Application of Reciprocity Writing Group in Writing Teaching [J]. North China Aerospace Industry. Journal of the hospital,2001 (1).

[9] Ma Rongqin.The Exploration of the Mode of Peer Revision of English Writing Based on WeChat Platform.2016, Xian Peihua University Project with the project number of PHKT20150741 